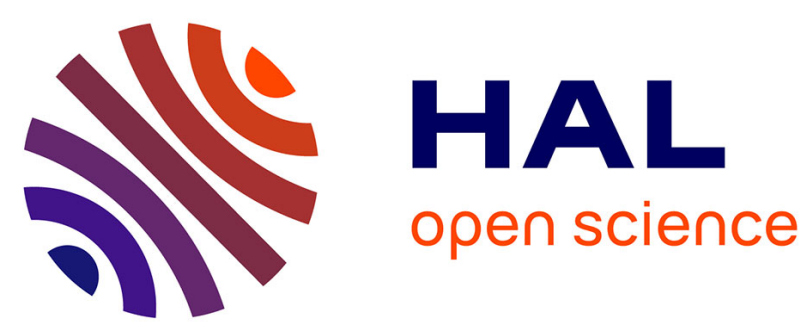

\title{
Maintenance of membrane organization in the aging mouse brain as the determining factor for preventing receptor dysfunction and for improving response to anti-Alzheimer treatments.
}

Julie Colin, Mélanie Thomas, Lynn Anne Pauron, Anthony Pinçon, Marie-Claire Lanhers, Catherine Corbier, Thomas Claudepierre, Frances T. Yen Potin, Thierry Oster, Catherine Malaplate-Armand

\section{- To cite this version:}

Julie Colin, Mélanie Thomas, Lynn Anne Pauron, Anthony Pinçon, Marie-Claire Lanhers, et al.. Maintenance of membrane organization in the aging mouse brain as the determining factor for preventing receptor dysfunction and for improving response to anti-Alzheimer treatments.. Neurobiology of Aging, 2017, 54, pp.84-93. 10.1016/j.neurobiolaging.2017.02.015 . hal-01595232

\author{
HAL Id: hal-01595232 \\ https://hal.science/hal-01595232
}

Submitted on 30 Nov 2020

HAL is a multi-disciplinary open access archive for the deposit and dissemination of scientific research documents, whether they are published or not. The documents may come from teaching and research institutions in France or abroad, or from public or private research centers.
L'archive ouverte pluridisciplinaire HAL, est destinée au dépôt et à la diffusion de documents scientifiques de niveau recherche, publiés ou non, émanant des établissements d'enseignement et de recherche français ou étrangers, des laboratoires publics ou privés. 

response to anti-Alzheimer treatments

Julie Colin ${ }^{1}$, Mélanie H. Thomas ${ }^{1}$, Lynn Gregory-Pauron ${ }^{1}$, Anthony Pinçon ${ }^{1}$, Marie-Claire

5 Lanhers $^{1}$, Catherine Corbier ${ }^{1}$, Thomas Claudepierre ${ }^{1}$, Frances T. Yen ${ }^{1}$, Thierry Oster $^{1 *}$, $6 \quad$ Catherine Malaplate-Armand ${ }^{1,2}$ *\#

$8 \quad{ }^{1}$ UR AFPA - INRA USC 340, EA 3998, Équipe Biodisponibilité et Fonctionnalité des Lipides $9 \quad$ Alimentaires (BFLA), Université de Lorraine, Nancy, F-54000, France

${ }^{2}$ Laboratoire de Biochimie et Biologie Moléculaire, UF Oncologie - Endocrinologie 11 Neurobiologie, Hôpital Central, Centre Hospitalier Universitaire, Nancy, F-54000, France

$12 *$ Co-senior authors

\# Corresponding author: Dr Catherine Malaplate-Armand, UR AFPA - INRA USC 340, Équipe Biodisponibilité et Fonctionnalité des Lipides Alimentaires (BFLA), Université de Lorraine, ENSAIA, 2 avenue de la forêt de Haye, Vandœuvre-lès-Nancy, F-54500, France Tel: +33-(3) 83595765 -E-mail address: catherine.malaplate-armand@univ-lorraine.fr

Abbreviations: $A \beta$, amyloid- $\beta$ peptide; $A D$, Alzheimer's disease; $A R A$, arachidonic acid; $C N T F$, ciliary neurotrophic factor; CNTF-R, CNTF receptor; DHA, docosahexaenoic acid; icv, intracerebroventricular; ip, intraperitoneal; PBS, phosphate-buffered saline; PUFA, 
Although aging is a major risk factor for Alzheimer's disease (AD), it is not considered in preclinical validation of anti-AD drugs. Here, the ciliary neurotrophic factor (CNTF)-associated pathway was chosen as a model to explore how aging affects neuronal reactivity to anti-AD agents. Comparison of the neuroprotective properties of CNTF in 6- and 18-month-old mice revealed an age-dependent CNTF resistance in the older animals associated with the exclusion of the CNTF-receptor subunits from raft to non-raft cortical membrane domains and their subsequent dispersion. This membrane remodelling prevented the formation of active CNTFreceptor complex and the activation of the pro-survival STAT-3 and ERK1/2 pathways in the aging brain. Moreover, CNTF-receptor distribution associated with CNTF signalling responses were improved in older mice receiving dietary docosahexaenoic acid, with CNTF-receptor functionality being similar to those of younger mice. In conclusion, age-altered membranes impair the reactivity of potential therapeutic targets. Dietary intervention could represent a promising adjuvant strategy to maintain functional neuronal membranes, thus allowing associated receptors to respond appropriately to anti-AD agents.

Keywords: brain aging, ciliary neurotrophic factor, dietary lipids, docosahexaenoic acid,lipid rafts, neuronal membranes

Highlights:

- Cortical membranes exhibit structural and functional changes in aging brain

- Membrane lipid composition and organization are key determinants for brain function

- Aging is associated with membrane protein relocation and loss of function

- Dietary DHA favors proper location and activity of membrane proteins in aging brain

- Preclinical Alzheimer's models should consider aging for improved relevance 


\section{Introduction}

Aging of the brain is a physiological process that reflects the long-term exposure of the individual to a number of environmental factors, including diet and lifestyle (smoking, alcohol consumption, etc.). Although age is an established risk factor for Alzheimer's disease $(A D)$, preclinical testing for drug development is often based on pathological $A D$ animal models without consideration of the aging process, which needs to be clearly understood in order to develop effective therapeutics for the elderly AD patient.

Numerous studies have provided strong evidence for associations between chronic conditions such as metabolic disorders and dyslipidaemia with AD-related cognitive decline (Frisardi et al., 2010), suggesting that disruption of lipid homeostasis is linked to risk of AD. Physiological brain aging has indeed been associated with alterations of lipid metabolism and bioavailability, including that of polyunsaturated fatty acids (PUFAs) such as the omega6 arachidonic (ARA) and omega-3 docosahexaenoic (DHA) acids (Gao et al., 2013; Taha et al., 2012), both of which influence membrane fluidity with consequences on brain functions including neurotransmission and synaptic plasticity. Furthermore, both qualitative and quantitative age-associated alterations in neuronal membrane lipid composition (Martín et al., 2010; Ohno-Iwashita et al., 2010) may affect a variety of cellular functions such as membrane fusion, receptor function, and activation of signalling pathways (Ledesma et al., 2012), all of which have been reported to be altered in AD. Lipid rafts serve as signalling platforms for these membrane-dependent cell activities, providing appropriate microenvironments for specific associations of receptors and signalling proteins, and the means to regulate cell functions including survival/death balance and neuroprotection (Davis et al., 2007; Sui et al., 2006). These highly-ordered cholesterol- and sphingolipid-rich membrane microdomains are distinct from non-raft regions, and their specific architecture can 
significantly influence receptor activation, signal transduction and related pathways, as well as $A \beta$ peptide release and cerebral vulnerability to neuronal stress conditions (Colin et al., 2016). We therefore initiated this study to evaluate age-dependent changes in these signalling platforms, as well as the functional consequences with regards to AD susceptibility.

To do this, we selected as a model the ciliary neurotrophic factor (CNTF), whose neuroprotective properties against $A \beta$-induced neuronal damage and behavioural impairment have previously been demonstrated in our in vivo AD model (Garcia et al., 2010). CNTF is of particular interest for this study since its effects result from its interaction with a tripartite CNTF-R receptor (CNTFR $\alpha /$ LIFR $\beta / g p 130)$ and the associated JAK-STAT transduction pathway, which depends on lipid raft architecture and composition (Sehgal et al., 2002). Furthermore, the CNTF-R activation depends on its two subunits gp130 and LIF-R that are located in possibly distinct microdomaines (Buk et al., 2004), but that must cluster together with CNTFR $\alpha$ in lipid rafts in order for transduction of CNTF signalling to occur (Port et al., 2007).

We show here that aging modulated the structural organization of neuronal membranes, resulting in altered functional properties of CNTF-R and significantly attenuated neuroprotective effect of CNTF. In contrast, the CNTF neuroprotective activity was maintained in older mice upon dietary DHA supplementation, demonstrating that dietary lipid-based preventive management could improve the efficiency of therapeutic agents by regulating the direct microenvironment of their targets in neuronal membranes.

\section{Materials and Methods}

\subsection{Chemicals and reagents}

All chemicals and reagents were obtained from Sigma, unless otherwise specified. $A \beta$ was obtained from Bachem, and soluble oligomers of $A \beta$ were prepared at the concentration of 

were stored at $-20^{\circ} \mathrm{C}$ until use. Analysis of oligomeric $A \beta$ preparations by electrophoresis in non-denaturing conditions indicated the presence of monomers, trimers and tetramers (Garcia et al., 2010). Soluble human CNTF was prepared at $1 \mu \mathrm{g} / \mu \mathrm{L}$ in sterile $0.1 \mathrm{M}$ phosphate buffered saline (PBS), $\mathrm{pH} 7.4$, and aliquots were stored at $-20^{\circ} \mathrm{C}$ until use.

\subsection{Animals and diets}

Adult male C57BL/6J mice aged 3 or 15 months were purchased from Janvier Breeding (Le Genest-St Isle, France). Animals were housed in pathogen-free, certified animal facility with access to food and water ad libitum. They were kept in a controlled environment $\left(22 \pm 1^{\circ} \mathrm{C}\right.$, $50 \pm 20 \%$ relative humidity) with a 12 -h light/dark cycle. At the beginning of the experiments, body masses of animals were (mean \pm SD) $24.1 \pm 0.2$ and $32.3 \pm 0.1$ grams, respectively. The group of young mice received a standard diet (StD, $3.08 \mathrm{kcal} / \mathrm{g}$ ), containing 18\% lipids (Harlan Laboratories, Gannat, France), while the older mice were randomly divided into 2 groups. One group received the StD diet, and the other group was placed on a DHA+ diet $(3.11 \mathrm{kcal} / \mathrm{g})$,

112 corresponding to the StD diet supplemented with $0.3 \%(w / w)$ DHA-ethyl ester (KD Pharma, 113 Bexbach, Germany). Animals received StD or DHA+ diet for 10 weeks. Animal handling and 114 experimental protocols were authorized in accordance with the European Communities 115 Council Directive (86/609/EEC) and the French Directive for animal experimentation $116(2013 / 118)$ for the use and care of laboratory animals and in conformity with PHS policy on 117 Humane Care and Use of Laboratory Animals, incorporated in the Institute for Laboratory 118 Animal Research Guide for Care and Use of Laboratory Animals. The experimental protocol 119 was approved by the institutional ethic committee (CELMEA-2012-0026). 
121 All surgical procedures were performed on mice anesthetized by intraperitoneal injection of

$1220.8 \%(\mathrm{w} / \mathrm{v})$ ketamine (Virbac, Carros, France) in physiological serum containing $0.1 \%(\mathrm{w} / \mathrm{v})$ 123 xylazine (Bayer HealthCare), at the dose of $1 \mathrm{mg}$ ketamine/10 g body weight. One $\mu \mathrm{L}$ of soluble $124 A \beta$ oligomers $(0.5 \mathrm{nmol}), \operatorname{CNTF}(1 \mu \mathrm{g})$, or saline were injected into the right ventricle 125 (stereotaxic coordinates from the bregma in mm: AP-0.22, L-1.0 and D 2.5) using a 10- $\mu \mathrm{L}$ 126 Hamilton microsyringe fitted with a 26-gauge needle as previously described (Garcia et al., 127 2010). After surgery, the mice were returned to their cages until the day of Y-maze testing, 128 which was 4 days after ICV injections. At the end of the experimental period, all animals were 129 anesthetized with isoflurane, followed by decapitation to remove the brain. Cortical tissues 130 were removed and immediately placed on ice and stored at $-80^{\circ} \mathrm{C}$.

\subsection{Evaluation of short-term memory}

132 Immediate spatial working memory performance was evaluated by recording spontaneous 133 alternation behaviour in a Y maze 4 days after icv injection, as described by Garcia et al. (2010).

\subsection{Duolink ${ }^{\circledR}$ labelling}

135 Mouse brains freshly dissected were immediately placed in pre-cooled $\left(-20^{\circ} \mathrm{C}\right)$ methylbutane 136 for $30 \mathrm{~min}$ at $-20^{\circ} \mathrm{C}$, removed and then stored at $80^{\circ} \mathrm{C}$. Brain sections (14- $\mu \mathrm{m}$ thickness) were 137 prepared using a cryostat HM550 (Microm-Microtech, Francheville, France) and then mounted 138 on gelatin-coated slides. Brain sections were fixed by treating with $4 \%(\mathrm{w} / \mathrm{v})$ paraformaldehyde in PBS for $15 \mathrm{~min}$ at room temperature, after which all steps were performed at room 140 temperature. After washing in PBS, the sections were stained using the Duolink ${ }^{\circledast}$ in situ kit 141 (Olink Bioscience, Uppsala, Sweden) according to manufacturer's instructions. This method is a 142 proximity ligation assay which allows the detection of two closely located proteins. To 143 evaluate the number of fluorescence spots corresponding to protein interaction, 
1445 independent fields were counted using a confocal microscope (Fluoview Fv10i, Olympus), for

145 brain sections from 3 mice, and quantification was performed using Image J image-processing 146 software (http://imagej.nih.gov).

\subsection{Preparation of protein homogenates}

148 Brain cortex tissues were dissected and immediately placed in RIPA lysis buffer (Millipore) 149 containing $1 \mathrm{mM}$ phenylmethylsulfonyl fluoride (PMSF), $1 \mathrm{mM}$ sodium orthovanadate and 150 cOmplete ${ }^{\mathrm{TM}}$ protease inhibitor cocktail (Roche). After homogenisation with a syringe through 151 a $23 G \times 1 \frac{11}{4}$ " needle, the samples were lysed using 2 cycles of freezing and thawing, and centrifuged at $4^{\circ} \mathrm{C}$ for $30 \mathrm{~min}$ at $10,000 \times g$ to collect supernatants. Protein concentrations in 153 the supernatants were determined by BCA (Thermo Fisher Scientific).

\subsection{Isolation of lipid rafts}

155 Preparation of membrane extracts and raft isolation were optimised based on the method

156 by Ledesma et al. (2003) and all steps were carried out at $4^{\circ} \mathrm{C}$. Brain cortex tissues were 157 homogenised in $10 \mathrm{mM}$ Tris buffer, $\mathrm{pH} 7.4$, containing $2 \mathrm{mM}$ EDTA, $0.32 \mathrm{M}$ sucrose, $1 \mathrm{mM}$ 158 PMSF and cOmplete ${ }^{\mathrm{TM}}$ protease inhibitors, using a Potter homogeniser followed by 15910 passages through a $23 \mathrm{G}$ needle. After centrifugation at $750 \times \mathrm{g}$ for $10 \mathrm{~min}$, the resulting 160 postnuclear supernatants were transferred to new tubes and total membrane fractions were 161 pelleted by ultracentrifugation at $100,000 \times g$ for $1 \mathrm{~h}$, prior resuspension in ice-cold MEST buffer, pH 7.4, containing 25 mM MES, 5 mM DTT, 2 mM EDTA, 1 mM PMSF, cOmplete ${ }^{\mathrm{TM}}$ protease inhibitors and $1 \%$ Triton $\mathrm{X}-100$. Samples were incubated $1 \mathrm{~h}$ on ice, homogenised again by 20 passages through a $23 \mathrm{G}$ needle and transferred into a discontinuous $5-45 \%$ sucrose gradient in 5-mL Ultra-Clear ${ }^{\mathrm{TM}}$ (Beckman Coulter) centrifugation tubes. Gradients were then subjected to buoyant density ultracentrifugation at $150,000 \times g$ for $18 \mathrm{~h}$, and 
1679 fractions of $500 \mu \mathrm{L}$ were collected consecutively from the top of each tube, with the order 168 being from 1 to 9 as the lowest to highest density. An aliquot from each fraction was 169 immediately mixed with $2 \times$ Laemmli buffer and denatured by boiling for immunoblot 170 analyses to assess the distribution of various proteins, while the remainder was stored at $171-20{ }^{\circ} \mathrm{C}$ for measurement of cholesterol levels using the Amplex ${ }^{\circledR}$ Red Cholesterol assay 172 (Invitrogen). Lipid rafts were considered as those fractions containing both flotillin-1 and 173 cholesterol peak levels.

\subsection{Immunoblot analyses}

175 Samples were mixed with $2 \times$ Laemmli buffer prior denaturation at $95^{\circ} \mathrm{C}$ for $5 \mathrm{~min}$. Samples 176 were then subjected to SDS-PAGE and immunoblotting. Reagents for electrophoresis were 177 purchased from BioRad and polyvinylidene fluoride membranes were from Millipore. The 178 following antibodies (1:1000 dilution) were used: rabbit monoclonal anti-CNTFR $\alpha$, anti-LIFR $\beta$ 179 and anti-gp130 antibodies (Santa Cruz Biotechnology), anti-P-STAT3 (STAT3 phosphorylated 180 on Tyr705) and anti-P-ERK1/2 (ERK1/2 phosphorylated on Tyr202/Thy204) antibodies (Cell 181 Signaling Technology), mouse monoclonal anti- $\beta$-tubulin (Sigma), anti-flotillin (BD 182 Biosciences), anti-STAT3 (Santa Cruz Biotechnology) and anti-ERK1/2 antibodies (Cell 183 Signaling Technology). Goat anti-rabbit IgG and horse anti-mouse IgG peroxidase-conjugated 184 secondary antibodies (Cell Signaling Technology) were detected using Supersignal 185 chemiluminescence (ECL kit; Millipore). Approximate molecular weights were estimated 186 using PageRuler prestained Protein Ladder Plus (Euromedex). Densitometric analysis of 187 immunoblot images was performed using the Fusion Fx5 Imaging System (Vilber Lourmat) 188 and ImageJ software. 
190 StatView software (SAS Institute) was used for the statistical analysis. Multiple pairwise

191 comparisons among the groups of data were performed using ANOVA, followed by a 192 Scheffe's post-hoc test. For data concerning the memory tests, statistical comparisons 193 among the datasets were made by one-way ANOVA, followed by Scheffe's post-hoc test. 194 Values of $p<0.05$ indicate significant differences between experimental groups. All reported 195 values represent the mean \pm SEM.

\section{Results}

\subsection{Impaired CNTF neuroprotective effect and CNTF-induced signalling pathways in aged mice}

CNTF has previously been reported to protect mice from neuronal damage and behavioural impairments that occur following a single icv administration of soluble $A \beta$ oligomers (Garcia et al., 2010). To study the effect of age on the neuroprotective effect of CNTF against AD-like symptoms, male C57BI/6J mice aged 6 (6-mo) or 18 (18-mo) months ( $n=6$ per 6 -mo group and $n=8$ per 18 -mo group) were injected icv with soluble $A \beta$ oligomers in the absence or presence of CNTF. Short-term spatial memory was then evaluated as \% alternation in the Y-maze test 4 days post-injection. We compared the results between young and old mice, with or without CNTF co-administration, using vehicle-injected mice as controls. No difference was observed in short-term memory performance in 6-mo and 18mo vehicle-injected mice (Fig1A). However, alternation was significantly lower in mice exposed to $A \beta$ oligomers than to vehicle, in mice of both age groups. This decrease was greater $(p<0.05)$ in the older mice $(69 \pm 1 \%$ vs. $50 \pm 2 \%$,) as compared to the younger animals ( $73 \pm 4 \%$ vs. $57 \pm 2 \%$ ), suggesting that $A \beta$-induced stress and subsequent short-term spatial memory impairment were more pronounced in the older animals (Fig1A). In 6-mo mice receiving co-administration of CNTF with $A \beta$, the \% alternation was not different than 
214 that measured in the control mice of the same age, demonstrating the neuroprotective

215 effect of CNTF against A $\beta$-induced spatial memory impairment. In contrast, CNTF provided 216 only partial protection against amyloid stress in 18 -mo mice, with the \% alternation of $A \beta$ 217 exposed aged animals being significantly lower $(p<0.01)$ than in the corresponding aged 218 controls (Fig1A). Treatment of CNTF alone did not induce any visible differences in \% 219 alternation when compared to that of saline-injected mice of the corresponding age group. 220 Also, the number of arm entries did not differ significantly among all experimental groups 221 (data not shown), indicating that the differences observed between the 2 groups were not 222 due to changes in exploratory, locomotor or motivational activities, nor from visual, 223 olfactory or tactile sensorial acuity.

A subgroup of the animals were euthanized $3 \mathrm{~h}$ following CNTF injection to determine the effect of age on CNTF-associated signal transduction. Despite identical amounts of CNTF injected into both young and old mice, the relative levels of phosphorylated forms of both STAT3 and ERK1/2 in cortical homogenates were significantly lower by $37 \pm 11 \%(p<0.05)$ and $75 \pm 5 \%(p<0.01)$, respectively, in 18 -mo mice as compared to 6 -mo animals (Fig1B and fig1C), suggesting impaired CNTF signalling and response in the older animals.

3.2. Loss of colocation of tripartite CNTF-R complex associated with exclusion from lipid rafts in brain cortex of 18-mo mice

Green fluorescent Duolink ${ }^{R}$ signals reflecting colocation and direct interactions between CNTF-R subunits were quantified and compared in brain cortex slices from 6-mo and 18-mo mice. Duolink ${ }^{R}$ spots indicating CNTFR $\alpha-$ LIFR $\beta$, CNTFR $\alpha-$ gp130 or LIFR $\beta$-gp130 colocation were significantly lower by $57 \pm 7 \%(p<0.01), 80 \pm 2 \%(p<0.001)$ and $61 \pm 4 \%(p<0.001)$, respectively, in the older mice as compared to younger animals (Fig2A). These subunits no longer located in close vicinity to each other, suggesting dramatically reduced interactions of 
the three CNTF-R subunits in brain cortex of older mice as compared to those of younger

239 animals. The Duolink ${ }^{R}$ assay was next used on cortical brain sections to determine the

240 location of the CNTF-R subunits relative to the raft-specific protein, flotillin-1 (Flot). Analysis

241 revealed numerous CNTFR $\alpha$-Flot, LIFR $\beta$-Flot and gp130-Flot interactions in 6-mo mice, 242 suggesting that CNTF-R subunits were primarily colocated in raft domains (Fig2B). In 243 contrast, Duolink ${ }^{R}$ signals in 18-mo mice for CNTFR $\alpha$-Flot, LIFR $\beta$-Flot and gp130-Flot were 244 strongly reduced by $88 \pm 4 \%(p<0.001), 83 \pm 2 \% \quad(p<0.001)$ and $47 \pm 8 \% \quad(p<0.01)$, 245 respectively, which demonstrated that in the cortex of older mice, the CNTF-R subunits were 246 excluded from lipid rafts and dispersed in other membrane domains.

247 3.3. Exclusion of CNTF-R subunits from lipid rafts associated with membrane remodelling in aged $248 \quad$ brain cortex

We next sought to determine potential differences in membrane domain composition 250 and organisation using brain cortical samples obtained from 6-mo and 18-mo mice. Lipid raft 251 fractions separated on sucrose gradients were considered as those containing the maximal 252 levels of flotillin-1 and cholesterol detected by immunoblot and fluorimetry, respectively. In 253 the cortical membranes from 6-mo mice, the three fractions (\# 6, 7 and 8) identified as 254 having the highest cholesterol and flotillin-1 levels were pooled to constitute the raft 255 subpopulation used in immunoblots. In contrast, raft domains in cortical membranes from 256 18-mo mice were identified in only one cholesterol- and flotilline-1-rich fraction (\#4), at a 257 lower density than those found in 6-mo mice (Fig3A and fig3B).

Cholesterol levels measured in the membrane fractions also appeared to be increased in 18-mo mice as compared to 6-mo mice, both fed the same StD diet (Fig3A). This was confirmed by the detection of 2.2 -fold higher $(p<0.001)$ cholesterol levels in the total 
membrane extracts from brain cortical tissues of older animals as compared to young

262 animals (Fig3C).

We used the cholesterol- and flotillin-1-enriched isolated raft fractions to measure the

264 levels of the CNTF-R subunits by immunoblot. No difference was observed in the levels of 265 these proteins in the total membrane extracts between both age groups (data not shown), 266 confirming that the decreased levels in the rafts (Fig2) was due to their exclusion from raft 267 domains. Indeed, a significant reduction of CNTFR $\alpha$ and LIFR $\beta$ levels by $58 \pm 4 \%(p<0.001)$ 268 and $41 \pm 3 \%(p<0.01)$, respectively, was revealed in the raft fraction of 18 -mo mice as 269 compared with 6-mo mice (Fig4). The third subunit of CNTF-R, gp130, could not be detected 270 in raft fractions due to limited sensitivity of immunoblot analysis, although its presence was 271 clearly demonstrated by immunohistochemical analyses (Fig2). These observations clearly 272 demonstrated that brain cortical membranes underwent significant age-related remodelling 273 that altered raft domain properties and lateral distribution of associated proteins such as the $274 \quad$ CNTF-R subunits that no longer cluster together in lipid rafts.

\subsection{Limitation of age-related remodelling and persistence of CNTF-R location in brain membranes} upon dietary DHA supplementation

Preliminary studies led us to measure a $15.3 \%$ enrichment of DHA $(p<0.001)$ in cortical

278 membranes of mice fed for 10 weeks with the DHA+ diet as compared to animals on StD diet.

279 In the present experiment, lipid analyses of brain cortical membranes obtained from 6-mo and 18-mo mice on StD diet showed no significant differences in either DHA levels relative to total fatty acid content, omega-6/omega-3 or ARA/DHA ratios (data not shown), which clearly indicates that the observed age-related changes were not due to discrepancies in DHA or PUFA levels between the young and older animals. 
A group of 18-mo mice was placed on DHA+ diet for 10 weeks, and then euthanized.

285 Cholesterol levels in total cortical membrane samples were found to be $37 \%$ lower $(p<0.01)$ in these mice as compared to those of mice of the same age on StD diet, and not significantly different from those of 6-mo mice fed the StD diet (Fig3C). Analysis of the membrane fraction profile of 18-mo mice on the DHA+ diet (Fig3A and fig3B) revealed raft domains of higher density (fractions 5 to 8 ) and lower cholesterol levels as compared to those of 18-mo mice on StD diet, demonstrating the ability of this fatty acid to influence membrane organisation and raft profile. Although cholesterol levels and flotillin-1 distribution in 18-mo mice on DHA+ diet were not identical to those of younger mice, the DHA-induced remodelling was visible enough to suggest an anti-aging effect by DHA on brain membranes. Indeed, an increase of CNTFR $\alpha$ and LIFR $\beta$ protein levels by $80 \pm 17 \%(p<0.01)$ and $44 \pm 5 \%(p<0.05)$, respectively, was observed in the raft fractions of 18-mo mice on the DHA+ diet, as compared to 18-mo mice on the StD diet (Fig4). Taken together, these data suggest that dietary DHA could not only prevent the increase of brain cholesterol in 18-mo mice, but also contributed towards limiting cortical membrane remodelling and preserving a CNTF-R subunit distribution profile in raft domains similar to that found in younger mice.

3.5. Sustained CNTF signalling and improved CNTF protective effects on learning and memory abilities in A $\beta$-exposed 18-mo mice upon dietary DHA supplementation and P-ERK1/2 levels were found to be significantly higher in 18-mo mice that received the DHA+ diet, by 2.7 and 3.5 fold $(p<0.01)$, respectively (Fig5A), as compared to those on StD diet. To determine whether CNTF neuroprotective effects could be improved in 18-mo mice that received the DHA+ diet, we also measured cognitive performance in the Y-maze following 
icv injection of soluble $A \beta$ oligomers. While there was no difference in the short-term memory capacity of vehicle-injected mice on StD or DHA+ diet (Fig5B), A $\beta$-induced decrease in alternation behaviour was significantly lower $(p<0.05)$ in the DHA+ group. Co-icv

311 administration of $A \beta$ oligomers and CNTF significantly reduced $A \beta$-induced memory 312 impairment in both diet groups. However, CNTF neuroprotection from the $A \beta$ toxic effect was 313 significantly higher $(p<0.01)$ in DHA+ mice than in StD mice. More importantly, in 18-mo mice 314 exposed to $A \beta$, the combined administration of DHA and CNTF maintained short-term memory capacities at the same levels as those found either in control 18-mo mice or in 6-mo A injected mice (Fig1A), suggesting that dietary DHA provided the means to maintain efficient CNTF signalling, as well as complete neuroprotection from amyloid stress in the older mice. Again, no alteration in exploratory, locomotor, visual or motivational capacities was observed during behavioural evaluation of any group of mice (data not shown).

\section{Discussion}

The present study demonstrates for the first time that neuronal membrane remodelling in the brains of 18-mo mice was associated with changes in CNTF receptor distribution and 325 efficacy of this cytokine as neuroprotective molecule.

Cell signalling by neurotrophic factors, including neurotrophin-3, nerve growth factor and 327 brain-derived neurotrophic factor as well as CNTF, is essential in the development of cognitive 328 functions such as learning and memory (Croll et al., 1998). Impaired signalling in aged 329 individuals and in pathological situations has been reported to be involved in memory deficits, and to result from altered expression of these neurotrophic factors rather than from changes in expression of their specific receptors (Kononen et al., 1995; Shi et al., 2010). Different 
333 patients or animal models, due primarily to reduced CNTF expression accompanied by either 334 unchanged or upregulated CNTF-R subunit levels (Nobbio et al., 2009; Soilu-Hänninen et al., 335 2010). Different studies based on treatment with neurotrophic factors also demonstrated that 336 they improve deficit in neurogenesis, synaptic plasticity and cognition in various AD mouse 337 models (Blanchard et al., 2010; Bolognin et al., 2014; Garcia et al., 2010; Kazim et al., 2014). 338 In this paper, we report that although icv injection of exogenous CNTF could provide complete protection from $A \beta$-induced neurotoxicity and memory impairment in young (6mo) mice, this beneficial effect was comparatively less pronounced in older (18-mo) mice. This clearly indicates that therapeutic strategies focusing on age-related diseases including AD elucidate the largely unknown mechanisms involved in the aging process, and most 347 particularly in the aging brain. injection of identical amounts of exogenous CNTF, the impaired response to CNTF was most likely due to the modified distribution of CNTF-R in the raft and non-raft cortical membrane fractions. Indeed, as a result of age-related neuronal membrane remodelling suggested by the distinct membrane fraction profiles and composition, our data revealed that in the cortex of 
18-mo mice, the three CNTF-R subunits were excluded from lipid rafts and dispersed in non-

357 raft cortical membrane domains, thereby altering their ability to form an active complex,

358 which may explain the impaired signalling in response to CNTF that was observed in these

359 animals. Cellular response to CNTF is triggered in lipid rafts upon specific binding to the GPI-

360 anchored CNTFR $\alpha$, which induces the heterodimerisation of gp130 and LIFR $\beta$, the two signal-

361 transducing subunits in a receptor complex (Davis et al., 1993; Port et al., 2007) that

362 transduces intracellular signalling cascades mainly via the activation of Janus kinases and

363 transcription factors of the STAT family (Heinrich et al., 1998). Thus, resistance to CNTF in the

364 older mice could result from inability of the subunits to build the active receptor, thereby

365 impairing CNTF neuroprotective signalling necessary to protect against $A \beta$ oligomer-induced

366 cytotoxicity in aged brain cortex. In view of these results, as well as the potential

367 microarchitectural and functional alterations of membrane domains in the older mice

368 compared to young animals, we would conclude that aging is a fundamental parameter to be

369 considered when using preclinical animal models to evaluate the responsiveness of

370 therapeutic targets located in neuronal membranes.

371 Brain cortical membranes of aged mice contained higher cholesterol levels as compared to

372 those of young individuals, which may have caused deleterious changes. A recent study

373 reported the redistribution of cholesterol in the membranes of hippocampal neurons from old

374 mice and rats, which was correlated with biophysical and biochemical changes occurring

375 within the lipid rafts favouring amyloidogenic APP processing (Marquet-de Rougé et al., 376 2013). We also recently reported an increased neurotoxicity of soluble $A \beta$ oligomers in a 377 dyslipidemic mouse model that is heterozygote for the lipolysis stimulated lipoprotein receptor, LSR. Old LSR+/- mice exhibited morphological changes in brain membranes (Stenger 379 et al., 2012), as well as increased cholesterol levels which were correlated with a higher 
susceptibility to $A \beta$-induced memory impairment (Pinçon et al., 2015). Taken together, these data indicate that the observed changes in membrane cholesterol content in the older mice are consistent with neurodegeneration and increased susceptibility to AD.

Our experiments revealed that dietary DHA provided a means to counter both the membrane cholesterol increase and the non-raft location of CNTF-R subunits in 18-mo mice. Indeed, 18-mo mice receiving DHA in the diet displayed both CNTF-R subunits clustering within the lipid raft domains or cortical membranes, as well as lower cortical cholesterol levels similar to those of the younger mice on StD diet. Lipid rafts are considered an important target for DHA whose effects are opposite to those of cholesterol with regards to raft physicochemical properties and organisation as well as to raft-associated protein activities in various cell types including neuronal cells (Grimm et al., 2011; Langelier et al., 2010; Schley et al., 2007; Shaikh et al., 2009). DHA treatment has been shown to affect the distribution of presenilin-1 in raft and non-raft fractions in neuroblastoma SH-SY5Y cells, leading to reduced $A \beta$ production (Grimm et al., 2011). On the contrary, $A \beta$ production was increased in neuronal cells in the presence of oxidized DHA, even at concentrations as low as 1\% (Grimm et al., 2016). Therefore, DHA content in neuronal membranes appears to be an essential parameter for neuronal function and survival.

The beneficial effects of DHA supplementation in the diet of the older mice were demonstrated by the restoration of CNTF-mediated signalling and neuroprotection from $A \beta$ oligomer-induced amyloid stress and cognitive impairment. This was consistent with previous reports showing that lipid status and metabolism are factors that influence both brain plasticity as well as susceptibility to $A \beta$ neurotoxicity (Florent-Béchard et al., 2009, 2007; Naudí et al., 2015). Also, high dietary intake of fish is associated with a lower risk of AD (Wu et al., 2015). Fish oil omega-3 PUFAs, and in particular DHA, have been widely reported to play a 
major neuroprotective role, due to their anti-inflammatory, pro-resolvin and anti-

405 amyloidogenic properties and via multiple pleiotropic mechanisms (Grimm et al., 2011;

406 Lorente-Cebrián et al., 2015; Oster and Pillot, 2010). Although the age-related alterations in

407 neuronal membranes reported in this study were not due to changes in DHA concentrations, it

408 is important to note the structural and functional impact of this PUFA as dietary 409 supplementation. DHA is known to be incorporated into brain membrane phospholipids, 410 mainly in phosphatidylethanolamine, and subsequently change the lateral distribution of 411 cholesterol and proteins (Shaikh et al., 2015), although its preferential incorporation in raft 412 domains is still under debate. Investigation is underway to determine the specific mechanisms 413 underlying the DHA protective effect.

In conclusion, our results suggest that dietary DHA could provide the means not only to prevent neuronal membrane changes and associated dysfunction of the aging brain, but also

416 to maintain reactivity to molecular therapeutic targets that would otherwise be absent or 417 impaired in the elderly AD patient. DHA-based adjuvant strategies to sustain the appropriate 418 membrane environment necessary for optimal function of membrane-associated proteins and 419 receptor therapeutic targets could be used in a poly-therapeutic approach towards the 420 treatment of AD.

Acknowledgements

423 The authors thank Marion Huguet, Annabelle Derrien and Laurent Royer for their excellent 424 technical assistance.

\section{Funding statements}

427 This research was supported by grants from the Lorraine Region and the French Society of 
428 Nutrition. JC and MT were recipients of a PhD fellowships from the Lorraine Region. MT and 429 AP were supported by grants from the France Alzheimer association and from the French 430 Ministry of Research and Higher Education, respectively.

\section{References}

Blanchard J, Wanka L, Tung Y-C, Cárdenas-Aguayo M del C, LaFerla FM, Iqbal K, Grundke-Iqbal

I. Pharmacologic reversal of neurogenic and neuroplastic abnormalities and cognitive impairments without affecting $A \beta$ and tau pathologies in 3xTg-AD mice. Acta Neuropathol (Berl) 2010;120:605-21

Bolognin S, Buffelli M, Puoliväli J, Iqbal K. Rescue of cognitive-aging by administration of a neurogenic and/or neurotrophic compound. Neurobiol Aging 2014;35:2134-46

Buk DM, Waibel M, Braig C, Martens AS, Heinrich PC, Graeve L. Polarity and lipid raft association of the components of the ciliary neurotrophic factor receptor complex in MadinDarby canine kidney cells. J Cell Sci 2004;117:2063-75

Colin J, Gregory-Pauron L, Lanhers M-C, Claudepierre T, Corbier C, Yen FT, Malaplate-Armand C, Oster T. Membrane raft domains and remodeling in aging brain. Biochimie 2016;130: 178-

\section{7}

Croll, SD, Ip NY, Lindsay RM, Wiegand SJ. Expression of BDNF and trkB as a function of age and cognitive performance. Brain Res 1998;812:200-8

Davis AR, Lotocki G, Marcillo AE, Dietrich WD, Keane RW. FasL, Fas, and death-inducing signaling complex (DISC) proteins are recruited to membrane rafts after spinal cord injury. J Neurotrauma 2007;24:823-34

Davis S, Aldrich TH, Stahl N, Pan L, Taga T, Kishimoto T, Ip NY, Yancopoulos GD. LIFR beta and gp130 as heterodimerizing signal transducers of the tripartite CNTF receptor. Science 
Florent-Béchard S, Desbène C, Garcia P, Allouche A, Youssef I, Escanyé M-C, Koziel V, Hanse M, Malaplate-Armand C, Stenger C, Kriem B, Yen-Potin FT, Olivier JL, Pillot T, Oster T. The essential role of lipids in Alzheimer's disease. Biochimie 2009;91:804-9

Florent-Béchard S, Malaplate-Armand C, Koziel V, Kriem B, Olivier JL, Pillot T, Oster T. Towards a nutritional approach for prevention of Alzheimer's disease: biochemical and cellular aspects. J Neurol Sci 2007;262:27-36

Frisardi V, Panza F, Solfrizzi V, Seripa D, Pilotto A. Plasma lipid disturbances and cognitive decline. J Am Geriatr Soc 2010;58:2429-30

Gao F, Taha AY, Ma K, Chang L, Kiesewetter D, Rapoport SI. Aging decreases rate of docosahexaenoic acid synthesis-secretion from circulating unesterified $\alpha$-linolenic acid by rat liver. Age Dordr Neth 2013;35:597-608

Garcia P, Youssef I, Utvik JK, Florent-Béchard S, Barthélémy V, Malaplate-Armand C, Kriem B, Stenger C, Koziel V, Olivier JL, Escanye M-C, Hanse M, Allouche A, Desbène C, Yen FT, Bjerkvig R, Oster T, Niclou SP, Pillot T. Ciliary neurotrophic factor cell-based delivery prevents synaptic impairment and improves memory in mouse models of Alzheimer's disease. J Neurosci 2010;30:7516-27

Grimm MOW, Haupenthal VJ, Mett J, Stahlmann CP, Blümel T, Mylonas NT, Endres K, Grimm HS, Hartmann T. Oxidized docosahexaenoic acid species and lipid peroxidation products increase amyloidogenic amyloid precursor protein processing. Neurodegener Dis 2016;16:44-54

Grimm, MOW, Kuchenbecker J, Grösgen S, Burg VK, Hundsdörfer B, Rothhaar TL, Friess P, de Wilde MC, Broersen LM, Penke B, Péter M, Vígh L, Grimm HS, Hartmann T. Docosahexaenoic acid reduces amyloid- $\beta$ production via multiple pleiotropic mechanisms. J Biol Chem 2011;286:14028-39 
Heinrich PC, Behrmann I, Müller-Newen G, Schaper F, Graeve L. Interleukin-6-type cytokine signalling through the gp130/Jak/STAT pathway. Biochem J 1998;334:297-314

Kazim SF, Blanchard J, Dai CL, Tung YC, LaFerla FM, Iqbal IG, Iqbal K. Disease modifying effect of chronic oral treatment with a neurotrophic peptidergic compound in a triple transgenic mouse model of Alzheimer's disease. Neurobiol Dis 2014;71:110-30

Kononen J, Hökfelt T, Pelto-Huikko M. Effects of aging on the expression of neurotrophins and their receptors in the rat pituitary gland. Neuroreport 1995;6:2429-34

Kriem B, Sponne I, Fifre A, Malaplate-Armand C, Lozac'h-Pillot K, Koziel V, Yen-Potin FT, Bihain B, Oster T, Olivier J-L, Pillot T. Cytosolic phospholipase A2 mediates neuronal apoptosis induced by soluble oligomers of the amyloid- $\beta$ peptide. FASEB J $2005 ; 19: 85-7$

Langelier B, Linard A, Bordat C, Lavialle M, Heberden C. Long chain-polyunsaturated fatty acids modulate membrane phospholipid composition and protein localization in lipid rafts of neural stem cell cultures. J Cell Biochem 2010;110:1356-64

Ledesma MD, Da Silva JS, Schevchenko A, Wilm M, Dotti CG. Proteomic characterisation of neuronal sphingolipid-cholesterol microdomains: role in plasminogen activation. Brain Res 2003;987:107-16

Ledesma MD, Martin MG, Dotti CG. Lipid changes in the aged brain: effect on synaptic function and neuronal survival. Prog Lipid Res 2012;51:23-35

Lorente-Cebrián S, Costa AGV, Navas-Carretero S, Zabala M, Laiglesia LM, Martínez JA, Moreno-Aliaga MJ. An update on the role of omega-3 fatty acids on inflammatory and degenerative diseases. J Physiol Biochem 2015;71:341-9

Marquet-de Rougé P, Clamagirand C, Facchinetti P, Rose C, Sargueil F, Guihenneuc-Jouyaux C, Cynober L, Moinard C, Allinquant B. Citrulline diet supplementation improves specific agerelated raft changes in wild-type rodent hippocampus. Age Dordr Neth 2013;35:1589-606 
Martín V, Fabelo N, Santpere G, Puig B, Marín R, Ferrer I, Díaz M. Lipid alterations in lipid rafts from Alzheimer's disease human brain cortex. J Alzheimers Dis 2010;19:489-502

Naudí A, Cabré R, Jové $M$, Ayala V, Gonzalo H, Portero-Otín M, Ferrer I, Pamplona R. Lipidomics of human brain aging and Alzheimer's disease pathology. Int Rev Neurobiol 2015;122:133-89

Nobbio L, Fiorese F, Vigo T, Cilli M, Gherardi G, Grandis M, Melcangi RC, Mancardi G, Abbruzzese M, Schenone A. Impaired expression of ciliary neurotrophic factor in CharcotMarie-Tooth type 1A neuropathy. J Neuropathol. Exp Neurol 2009;68:441-55

Ohno-Iwashita $Y$, Shimada $Y$, Hayashi M, Inomata M. Plasma membrane microdomains in aging and disease. Geriatr Gerontol Int 2010;10:S41-52

Oster T, Pillot T. Docosahexaenoic acid and synaptic protection in Alzheimer's disease mice. Biochim Biophys Acta 2010;1801:791-8

Pinçon A, Thomas MH, Huguet M, Allouche A, Colin JC, Georges A, Derrien A, Lanhers M-C, Malaplate-Armand C, Oster T, Corbier C, Pillot T, Olivier JL, Yen FT. Increased Susceptibility of Dyslipidemic LSR+/- Mice to Amyloid Stress is Associated with Changes in Cortical Cholesterol Levels. J Alzheimers Dis 2015;45:195-204

Port MD, Gibson RM, Nathanson NM. Differential stimulation-induced receptor localization in lipid rafts for interleukin- 6 family cytokines signaling through the gp130/leukemia inhibitory factor receptor complex. J Neurochem 2007;101:782-93

Schley PD, Brindley DN, Field CJ. (n-3) PUFA alter raft lipid composition and decrease epidermal growth factor receptor levels in lipid rafts of human breast cancer cells. J Nutr 2007;137:54853

Sehgal PB, Guo GG, Shah M, Kumar V, Patel K. Cytokine signaling: STATS in plasma membrane rafts. J Biol Chem 2002;277:12067-74 
Shaikh SR, Kinnun JJ, Leng X, Williams JA, Wassall SR. How polyunsaturated fatty acids modify molecular organization in membranes: insight from NMR studies of model systems. Biochim Biophys Acta 2015;1848:211-9

Shaikh SR, Rockett BD, Salameh M, Carraway K. Docosahexaenoic acid modifies the clustering and size of lipid rafts and the lateral organization and surface expression of MHC class I of EL4 cells. J Nutr 2009;139:1632-9

Shi SS, Shao SH, Yuan BP, Pan F, Li ZL. Acute stress and chronic stress change brain-derived neurotrophic factor (BDNF) and tyrosine kinase-coupled receptor (TrkB) expression in both young and aged rat hippocampus. Yonsei Med J 2010;51:661-71

Soilu-Hänninen M, Broberg E, Röyttä M, Mattila P, Rinne J, Hukkanen V. Expression of LIF and LIF receptor $\beta$ in Alzheimer's and Parkinson's diseases. Acta Neurol Scand 2010;121:44-50

Stenger C, Pinçon A, Hanse M, Royer L, Comte A, Koziel V, Olivier J-L, Pillot T, Yen FT. Brain region-specific immunolocalization of the lipolysis-stimulated lipoprotein receptor (LSR) and altered cholesterol distribution in aged LSR+/- mice. J Neurochem 2012;123:467-76

Sui Z, Kovács AD, Maggirwar SB. Recruitment of active glycogen synthase kinase-3 into neuronal lipid rafts. Biochem Biophys Res Commun 2006;345:1643-8

Taha AY, Gao F, Ramadan E, Cheon Y, Rapoport SI, Kim HW. Upregulated expression of brain enzymatic markers of arachidonic and docosahexaenoic acid metabolism in a rat model of the metabolic syndrome. BMC Neurosci 2012;13:131

Wu S, Ding Y, Wu F, Li R, Hou J, Mao P. Omega-3 fatty acids intake and risks of dementia and Alzheimer's disease: a meta-analysis. Neurosci Biobehav Rev 2015;48:1-9 


\section{Figure legends}

550 Fig.1. Comparison of CNTF-mediated neuroprotection and related signalling pathways in 6-mo and 18-mo mice

552

(A) Mice received icv injections of $A \beta$ oligomer \pm CNTF or vehicle, followed by a Y-maze test 4 days post-injection. Alternation data are presented as means \pm SEM ( $n=6$ per 6 -mo group and $\mathrm{n}=8$ per 18 -mo group). (B, C) Three hours post-injection, CNTF-treated mice were euthanized and cortical protein homogenates were prepared. STAT3, P-STAT3 (B), ERK1/2 and P-ERK1/2 (C) proteins were analysed by immunoblot. Representative blots are shown and densitometry was performed. P-STAT3/STAT3 and P-ERK1/2/ERK1/2 relative ratios were calculated and results are shown as means \pm SEM $(N=3$ separate blots, $n=3$ mice chosen randomly per group). Significant differences between groups are indicated as $*(p<0.05)$, $(p<0.01)$ and $* * *(p<0.001)$.

Fig.2. Comparison of CNTF-R subunit clustering and location in 6-mo and 18-mo mouse brain cortical membranes

Interactions of CNTFR $\alpha$, LIFR $\beta$ and gp130 (A) with each other or (B) with flotillin-1 (Flot) were studied in the cortex of 6-mo and 18 -mo mice by Duolink ${ }^{R}$ analysis, and spots indicating colocation were detected using fluorescence microscopy and quantified with Image J. A representative image is presented for each interaction. Results are presented as means \pm SEM ( $N=5$ separate fields, $n=2$ mice chosen randomly per group). Significant differences between 6mo and 18-mo animals are indicated as $* *(p<0.01)$ and $* * *(p<0.001)$.

Fig.3. Effects of age and dietary DHA on flotillin-1 and cholesterol distribution in brain cortical membranes 

DHA+ diet for 10 weeks were treated with Triton X-100 and separated on sucrose gradient as described in the Materials and Methods section. Distribution of flotillin-1 (A, B) and cholesterol (A) was assessed in the various samples and representative profiles are shown for each group ( $n=6$ mice chosen randomly per group).

(C) Membrane cholesterol was measured in total membrane extracts. Results are presented as means \pm SEM ( $n=6$ mice chosen randomly per group). Significant differences between groups are indicated as $* *(p<0.01)$ and $* * *(p<0.001)$.

Fig.4. Effects of age and dietary DHA supplementation on CNTF-R subunit location in raft $* *(p<0.01)$ and $* * *(p<0.001)$.

Fig.5. Effects of dietary DHA supplementation on CNTF-activated signalling pathways and on learning and memory abilities of 18 -mo mice treated with $A \beta$ oligomers Mice aged 18-mo were fed StD or DHA+ diet for 10 weeks, followed by icv injection of $A \beta$ oligomers \pm CNTF. (A) Three hours post-injection, CNTF-treated animals were euthanized, and brain cortical protein homogenates were prepared. Total and phosphorylated STAT3 and ERK1/2 protein levels were quantified by densitometry of immunoblots. Representative blots 
597 are shown and P-STAT3/STAT3 as well as P-ERK1/2/ERK1/2 ratios are shown as means \pm SEM 598 ( $N=3$ separate immunoblots, $n=3$ mice chosen randomly per group). Significant differences 599 between the diet groups are indicated as $* *(p<0.01)$. (B) Four days post-injection, spontaneous 600 alternation in the $\mathrm{Y}$ maze was measured as described for Fig1A. Results are shown as means \pm 601 SEM ( $\mathrm{n}=8$ mice per group). Significant differences between groups are indicated as $*(p<0.05)$, 602 $* *(p<0.01)$ and $* * *(p<0.001)$. 